\title{
The Application of the New Reinforcement Bridge Technology with Prestressed CFRP Plate
}

\author{
Baojing Zhang ${ }^{a, *}$ and Shouping Shang \\ School of Civil Engineering, Hunan University, Changsha Hunan 410082, China \\ azhangbaojing2009@163.com
}

Keywords: Bridge strengthening; Prestress; CFRP plate; Tension technology; Loss of prestress.

\begin{abstract}
It briefly introduces the characteristics of prestressed CFRP plate and the new reinforcement bridge technology of prestressed CFRP plate and conducts a theoretical analysis on the principle of reinforcement design in this paper. ZhuJinDu Bridge is provided with reinforcement design by the prestressed CFRP plate reinforced new technology according to the test report issued by inspection unit as well as the respective analysis on the reinforcement design scheme and the tensioning process, finally it sketches the test results of research group on the strengthened bridge. The results show that the new reinforcement bridge technology of prestressed CFRP plate has the advantages of simple operation, short duration, obvious economic benefit and favorable reinforcement effect, and its successful application for the ZhuJinDu Bridge indicates that this reinforcement method is worth promoting and applying for the domestic engineering projects of the same type.
\end{abstract}

\section{Introduction}

Our nation has gone through a period of rapid development of basic construction and numerous bridges and houses have been built since the founding. With the increase of service life, many bridges built in the early stage of the founding of the nation confronted with demolition and reconstruction or reinforcement due to sorts of reasons as improving standards, improper design and construction, increasing load, material aging, environmental corrosion, alteration of function, etc. Demolition and reconstruction are bound to bring great economic burden to the state and society, but there are defects in the traditional reinforcement method as difficult construction, long project duration, poor corrosion resistance and poor durability, etc. The reinforced bridge technology of prestressed CFRP plates has been one of the reinforced technologies with rapid development at home and abroad in recent years, the prestressed CFRP plates can make full use of high strength performance of CFRP plates and improve the bonding force stress distribution on the interface between CFRP plates with concrete so as to delay the debonding failure of CFRP. The research on prestressed CFRP plates reinforced concrete members has attached profound attention at home and abroad and has obtained a lot of achievements in recent years due to the superiorities of CFRP plates of high tensile strength, strong corrosion resistance, convenient design and simple construction, etc1 4.

The research group has devoted on the study of the new technology of prestressed CFRP plate reinforcement since 2003, and achieved a series of theoretical results and developed a set of prestressed CFRP plate anchorage along with tensioning mechanical device (this set of device has won two national patents), the technology currently has been successfully applied to the reinforcement of the practical projects as the JinGangTou Bridge inLiuyang City of Hunan province, the JieFang Bridge in Xiangtan County of Hunan Province and the ZhuJinDu Bridge in Xiangxiang City of Hunan province. The new technology of prestressed CFRP plate reinforcement on the bridge belongs to the international advanced technology, this paper takes the ZhuJinDu Bridge in Xiangxiang City of Hunan province as the paradigm project to introduce the reinforcement scheme and tensioning processas well as the observation of the long-term prestress loss. 


\section{Reinforcement Technology of Prestressed CFRP Plate}

\subsection{Material Performance}

Carbon fiber plate is mainly used in the new technology of prestressed CFRP plate reinforcement and compared with other reinforcement materials, carbon fiber plate has the following characteristics: (1) high tensile strength, the imported carbon fiber plate can reach about $3000 \mathrm{MPa}$; (2) light material and its density is $1 / 5$ of steel materials; (3) strong corrosion resistance, it does not generate the electrochemical corrosion, and the intensity rarely decreases under the effects of chloride, carbonic acid and caustic soda, etc; (4) good fatigue resistance, the prestress of prestressed CFRP plate significantly perfects the section stress distribution of bending members, reduces the steel stress and the structural deformation and greatly improves the fatigue life of member5.

\subsection{Technical Characteristics}

He new technology of prestressed CFRP plate reinforcement mainly has the following superiorities compared to traditional bridge reinforcement technology: (1) it has good reinforcement effect, the traditional reinforcement method belongs to passive stress reinforcement while reinforcement technology of prestressed CFRP plate transforms the passive stress to the active stress reinforcement, it reduces the stress lag of the reinforcement materials and makes the full use of the strength of reinforcement material. In addition, material quality of CFRP plate is relatively light which will not increase the deadweight of the bridge with a favorable reinforcement effect; (2) convenient construction; it doesn't not need large machines just operated with several people due to relatively light material quality of CFRP plate and exquisite tensioning and anchoring device; (3) good durability; nice corrosion resistance of CFRP plate ensures the long-time use; (4) low comprehensive cost; compared with other reinforcement methods, the operation of this technology is simple and convenient with short construction period and less material, which can save investment with small maintenance workload in the later stage.

\subsection{Theoretical Analysis on Bridge Reinforcement}

\subsubsection{Basic Assumption}

Before conducting the theoretical derivation design of the new reinforcement bridge technology with prestressed CFRP plate in this paper6, the basic assumptions are shown as follows:

(1) Bend and deformation of members are in line with the plane cross-section assumption; (2) there are no slippage or continuous stress and strain between stressed steel with concrete as well as the carbon fiber and concrete; (3) the strain of concrete on the compression zone edge of original structure will reach the limit value in the ultimate state, and the stress of compression zone of section can be simplified is rectangular calculation, and the compressive strength design value is applied for concrete; (4) considering the phase stress when reinforcing the bridge, the constant load is beard by the original structure section before the effective combination of new materials with the original structure (component), the load(dead load, live load and attached load)after the effective combination is beard by reinforced composite section; (5) steel is considered to be an ideal elastic-plastic material land don't take the strength improved by the strengthening part into account, the stress-strain relation is: $\sigma_{s}=E_{s} \varepsilon_{s}\left(\varepsilon_{s} \leq \varepsilon_{y}\right), \sigma_{s}=f_{y}\left(\varepsilon_{s}>\varepsilon_{y}\right)$.

Where: $\sigma_{s}$ - steer stress; $E_{s}$ - elastic modulus of steer bar; $\varepsilon_{s}$ - Strain of steer; $f_{y}$ - Yield strength of steel bar.

(6) the CFRP plate is considered to be a completely elastic material in tensioning stage and the stress-strain relation is: $\sigma_{f}=E_{f} \varepsilon_{f}$.

where; $\sigma_{f}$-stress of CFRP plate; $E_{f}$ - Tensile modulus of elasticity of CFRP plate; $\varepsilon_{f}$-strain of CFRP plate.

\subsubsection{Reinforcement Design Principle}

The normal section of the CFRP plate strengthened beam is basically rectangular, $T$ or I shape, and it can be simplified as rectangular section when conducting the calculation of reinforcement, the reinforced normal section is shown in figure 1. 

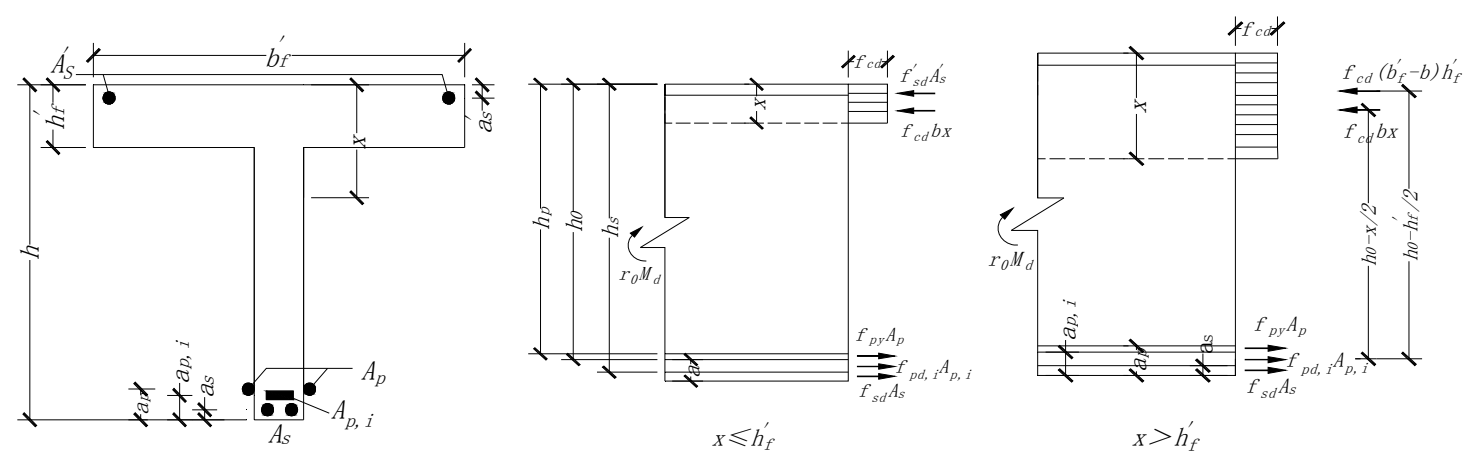

Fig.1 Normal section diagram of CFRP Plate Fig.2 Flexural capacity calculation diagram of section diagram Fig.3 Flexural capacity calculation diagram of section diagram

The calculation on the flexural capacity of the strengthened beam bridge structure should be on basis of two cases according to the section shape of the beam and the position of neutral shaft:

(1) Rectangular section or the neutral axis is in the T shape or the I shape section wing plate $\left(x \leq h_{f}^{\prime}\right)$, and its calculation diagram of flexural capacity of normal section is shown in figure 2.

Calculating is in accordance with formula (1) and (2).

$$
\begin{aligned}
& f_{c d} b_{f}^{\prime}+f_{s d}^{\prime} A_{s}^{\prime}=f_{p y} A_{p}+f_{p d, i} A_{p, i}+f_{s d} A_{s} \\
& r_{0} M_{d} \leq f_{c d} b_{f}^{\prime} x\left(h_{0}-\frac{x}{2}\right)
\end{aligned}
$$

(2) T shape or I shape section and the neutral axis are in the section web (), and its calculation diagram of flexural capacity of normal section is shown in Figure 3.

Calculating is in accordance with formula (3) and (4).

$$
\begin{aligned}
& f_{c d} b x+f_{c d}\left(b_{f}^{\prime}-b\right) h_{f}^{\prime}+f_{s d}^{\prime} A_{s}^{\prime}=f_{p y} A_{p}+f_{p d, i} A_{p, i}+f_{s d} A_{s} \\
& r_{0} M_{d} \leq f_{c d} b x\left(h_{0}-\frac{x}{2}\right)+f_{c d}\left(b_{f}^{\prime}-b\right) h_{f}^{\prime}\left(h_{0}-\frac{h_{f}^{\prime}}{2}\right)+f_{s d}^{\prime} A_{s}^{\prime}\left(h_{0}-a_{s}^{\prime}\right)
\end{aligned}
$$

where: $r_{0}$ is the importance coefficient of bridge structure; $M_{d}$ is the calculated sectional bending moment combination design value; $f_{p y}$ is the tensile strength design value of prestressed CFRP plate; $A_{p}$ is the area of CFRP plate; $f_{p d, i}$ and $A_{p, i}$ are tensile strength design value and sectional area of prestressed steer in original beam respectively; $A_{s}$ and $A_{s}^{\prime}$ are the sectional area of the longitudinal tension and compression of the original beam and the ordinary steel bar respectively; $f_{s d}$ is the tensile strength design value of ordinary steel with longitudinal reinforcement in original beam; $f_{c d}$ is the tensile strength design value of concrete; $b_{f}^{\prime}$ is the effective width of compressed wing plate; $b$ is the width of rectangular section or width of T shape section web; $h_{f}^{\prime}$ is the thickness of compressed wing plate; $h_{0}$ is the distance from the resultant force (ordinary and internal prestressed steels)of the external prestressed CFRP plate and the original beam steel to the top surface of the beam.

(3)Height checking of section compression zone after reinforcement

The height of the section compression zone in the above formulas shall meet the following conditions to ensure that the reinforced concrete beam is still plastic failure:

$x \leq \xi_{b} h_{s}$ or $x \leq \xi_{b} h_{p}, x \geq 2 a_{s}^{\prime}$

$h_{s}$ and $h_{p}$ are the distance from the resultant force of the ordinary steel and the prestressed steel in the original beam to the top surface of the beam respectively; $h_{0}$ is the distance from the resultant force of the external prestressed CFRP plate and the original beam steel (ordinary and internal prestressed steels)to the top surface of the beam; $a_{s}^{\prime}$ is the distance from the resultant force of the normal steel bar in the compression zone to the edge of compression; $\xi_{b}$ is the height of relative limit compression zon e of the original prestressed concrete beam.

Which is derived by formula (6):

$$
a_{1} f_{c d} b x\left(h_{0}-\frac{x}{2}\right)=M
$$


$a_{1}$ is the coefficient, concrete strength is 1.0 when $C \leq 50 ; M$ is the sectional bending capacity after reinforcement of CFRP plate, which is equal to the sum value of the measured sectional bending capacity and sectional capacity provided by the prestressed CFRP plate.

\section{The Application of the New Reinforcement Technology with Prestressed CFRP Plate in Projects}

\subsection{General Situation}

Zhu Jin-du bridge of Xiangtan City is located within Xiangxiang City and is the 320 State Road car-special line project that accomplished in 1999. The overall length of the bridge is $306.24 \mathrm{~m}$ and the form of superstructure is: $2 \times 30 m+2 \times 50 m+4 \times 30 m+20$ mprestressed concrete continuous variable cross section box beam; multi column pier is adopted at the substructure, the abutment is pile-column type and the bearing is plate-rubber. The foundations are all bored pile foundation. Design load: automobile -20 , trailer- 100 , bridge deck width: $0.50 \mathrm{~m}$ (anti-collision guardrail) $+12 \mathrm{~m}$ (clear width) $+0.50 \mathrm{~m}$ (anti-collision barrier) $=13.0 \mathrm{~m}$.

Highway Bureau of Xiangtan City deputed relevant inspection units to conduct a comprehensive inspection of the bridge in May, 2012 and the main results are:

(1) The technical status score of overall bridge is rated $\mathrm{Dr}=55.43$, and the technical status rating of overall bridge is evaluated as the fourth class - the bad state, which needs overhaul or reconstruction with traffic control in time. (2) the flexural capacity of mid-span and the fulcrum as well as the shear capacity of the fulcrum and the adjacent section are checked and it indicates that the bearing capacity of existing condition for the bridge can not meet the requirements of highway - II load standards, it should be reinforced or reconstructed. (3) The vibration of the whole bridge beam is obvious, which is related to the relatively poorly overall stiffness of the bridge. The dynamic analysis of the bridge beam shows that the first order fundamental frequency of the bridge is $\mathrm{Fd}=2.14 \mathrm{~Hz}<2.45 \mathrm{~Hz}$ (the smallest first order fundamental frequency), which is lower than the bridges with the same type of the same span.

\subsection{Reinforcement Design Scheme}

The author has proposed the following reinforcement design schemes on basis of the detection results of bridge: (1) mid-span bending moment reinforcement: uniform section box-girder is reinforced with prestressed CFRP plate at the mid-span substrate (Figure 4); variable section box-girder is reinforced and tensioned with prestressed CFRP plate at the side of web in the mid-span box (Figure 4). (2) Supports hogging moment reinforcement: the roof surface of the box girder is reinforced with prestressed CFRP plate (Figure 3, Figure 4). (3) Support shear: high performance cement composite mortar steel mesh layer is applied for reinforcing on the web-side of the box girder, and reinforcement thickness of both sides of the vertical web of box girder is $5 \mathrm{~cm}$ (Figure 5). (4) Increase of 50m-span stiffness: Adding the vertical rib plate at the both sides of pier supports of 2, 3, $4 \#$ with the $50 \mathrm{~m}$-span to increase the stiffness of the bridge.
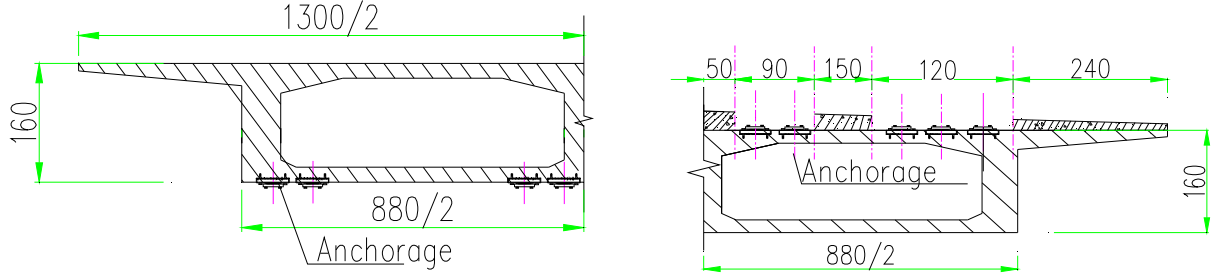

Fig.4 Anchorage layout on substrate and roof of box girder 

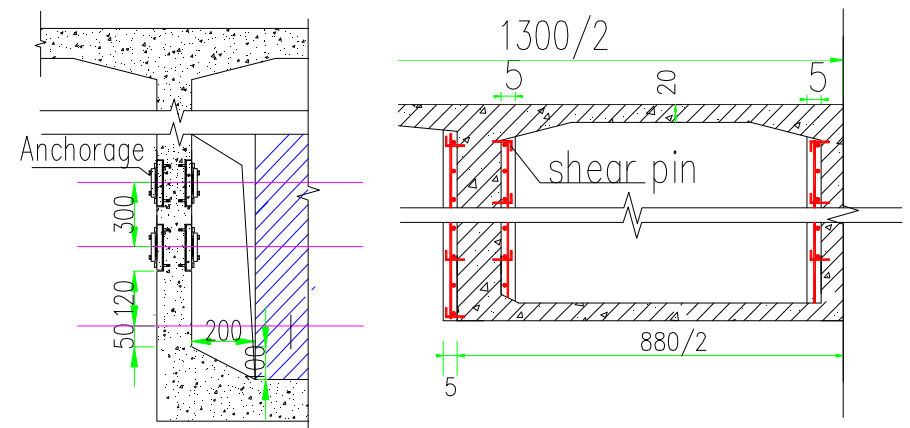

Fig.5 Anchorage layout and HPFL reinforcement section of box girder web

\subsection{Comparison of Calculated Results before and after the CFRP Plate Reinforcement}

It has calculated the increased flexural capacity and the safety factor of the mid-span section after the Zhu Du bridge reinforced with prestressed CFRP plate and the calculated results are shown in Table 1, it can be seen from table 1 that the bridge safety factor is greater than 1 after the reinforcement; and the height of compression zone after reinforcement meets the requirements of formula (5) in this paper after checking.

Tab. 1 comparison of calculated results

\begin{tabular}{c|c|c|c|c}
\hline Item & $\begin{array}{c}\text { 1)Design } \\
\text { loadMu(kN·m) }\end{array}$ & $\begin{array}{c}\text { 2)Measured section } \\
\text { resistanceMn(kN·m) }\end{array}$ & $\begin{array}{c}\text { 3)CFRP reinforcement } \\
\text { increases resistance M } \\
(\mathrm{kN} \cdot \mathrm{m})\end{array}$ & $\begin{array}{c}\text { Coefficient of safety after } \\
\text { reinforcement(2)+(3)/(1) }\end{array}$ \\
\hline First span & 37134.7 & 31538.9 & 6875 & 1.034 \\
\hline $\begin{array}{c}\text { Third } \\
\text { span }\end{array}$ & 26444.6 & 20682.4 & 7734 & 1.075 \\
\hline $\begin{array}{c}\text { Fourth } \\
\text { span }\end{array}$ & 26893.7 & 20682.4 & 7734 & 1.057 \\
\hline $\begin{array}{c}\text { Sixth } \\
\text { span }\end{array}$ & 27478.1 & 26022.1 & 8750 & 1.262 \\
\hline $\begin{array}{c}\text { Seventh } \\
\text { span }\end{array}$ & 20911.9 & 20682.4 & 8750 & 1.407 \\
\hline $\begin{array}{c}\text { Eighth } \\
\text { span }\end{array}$ & 21352.5 & 20682.4 & 8750 & 1.378 \\
\hline $\begin{array}{c}\text { Ninth } \\
\text { span }\end{array}$ & 12470.9 & 12330.5 & 6563 & 1.515 \\
\hline
\end{tabular}

\subsection{Tensioning Process}

The operation of new technology of bridge reinforcement with prestressed CFRP plate is simple and convenient which can be completed manually without large machines, and the tensioning process mainly contains the following steps:

(1) The preparatory work before tensioning mainly contains labor division, preparation of tensioning equipment and anchorage device along with carbon plate cutting.

(2) Anchorage, tensioning equipment and carbon plate position should be measured and set out according to the design drawings.

(3) Surface treatment of concrete structure; cutting out a certain depth of concrete notch at the fixed position of anchorage device and tensioning equipment in accordance with the design requirements to ensure the surface of anchorage of tensioning equipment is on the same plane with concrete surface of bridge so as to lay the anchorage device and tensioning equipment, shown as figure 6.

(4) Post-installed rebar and the installation of anchorage, tensioning equipment and carbon plate. The depth of post-installed rebar should meet the design requirements, and the adhesive for post-installed rebar is applied that developed by this research group. When the post-installed rebar adhesives reach the design strength, the anchorage device, tension equipment and carbon plate are installed to ensure the carbon plate, anchorage and tensioning equipment at centering, and a layer of epoxy structural adhesive is applied at the junction of carbon plate and concrete so that carbon plate 
and concrete can be integrated as a whole. The anchorage end of carbon plate is fixed and the bolt is tightened on basis of the torque of each bolt using the torque wrench in accordance with design requirements, shown in figure 6.
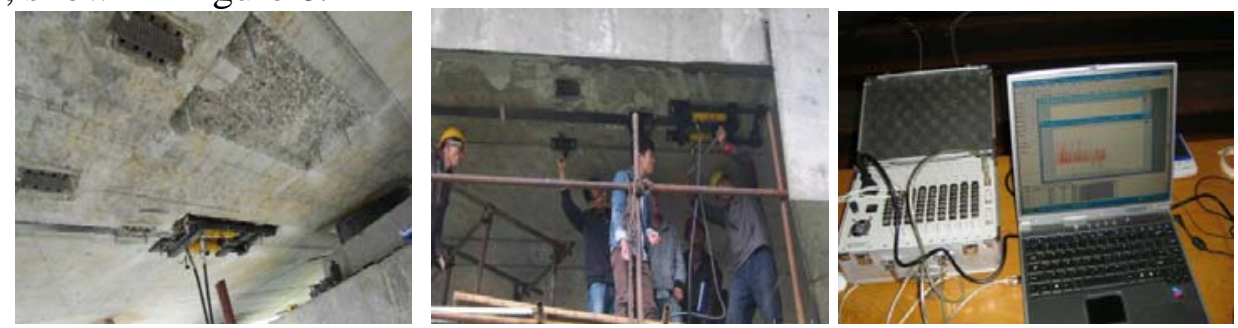

Fig.6 Field reinforcement map

(5)Carbon plate tension: CFRP plate tension using Synchronous jack is under dual control of the stress and strain and the tensioning stress is controlled by oil pressure gauge7, in addition, its tensioning stress is controlled with instrument by the observation on the changes in the resistance strain gauge bonded on the surface of CFRP plate, shown in figure 6. The creep crack properties of CFRP plate should be taken into account according to the "Structural design and construction guidelines of externally bonded FRP reinforced concrete" of the America so that the maximum tensile stress of CFRP plate shall not exceed the 55\% of the ultimate strength in the reinforcement design8, tension controlled stress is $1000 \mathrm{MPa}$ which as $45 \%$ of measured ultimate tensile strength of CFRP plate when it considers that there may exist small eccentricity in tension resulting in poor play of the strength of CFRP plate in the reinforcement design. The CFRP plate is subjected to be graded loaded with the loading force at each class is $10 \%$ of the tensile controlled stress. It shall prevail the measured results of stress when the measured results of stress and strain are inconsistent, but the measured strain shall not exceed $15 \%$ of the initial strain9.

(6)Fixing the tensioning ends of CFRP plate, the bolt is tightened on basis of the torque of each bolt using the torque wrench in accordance with design requirements (CFRP plate is easy to be broken due to the low shear strength, so the design requirements of the anchorage are relatively high, especially the design of anchorage ridges and bolt torque). Loading the jack off and then removing the tensioning machine top rune the tensioning ends of CFRP plate.

(7)The optical fiber grating sensor is pasted on the surface of the CFRP plate so as to conduct the test observation on the long-term creep of the CFRP plate in the later stage10, as shown in Figure 6.

(8)Every other $1 \mathrm{~m}$ on the surface of the CFRP plate is installed with one angle steel batten, and then on the surface of the CFRP plate is applied with the composite mortar to protect carbon plate from destruction of external factors, later the anchorage of the both ends of the CFRP plate is filled and applied with composite mortar to prevent the corrosion on anchorage.

\subsection{Reinforcement Effect Detection}

The reinforcement effect of the bridge was detected with static and dynamic load experiment tests by the research group after the completion of the bridge reinforcement in July 2013, and it obtained the following conclusions: (1) static load test: the relative residual deformation and relative residual strain were less than $20 \%$ after each measuring point unloaded under each test conditions, which met the requirements of the "Code for inspection and evaluation of bearing capacity of Highway Bridges" and it indicated that structure was in the elastic state under the test load; when each test conditions was of full load, the maximum deflection calibration coefficient was 0.871 and the strain calibration coefficient was 0.889 , both met the requirements " the calibration coefficient shall be less than 1 ” in the "Code for inspection and evaluation of bearing capacity of Highway Bridges", in indicated that the actual stiffness and strength of structure were larger than the theoretical value with certain emergency capecity. (2) Dynamic load test: the measured first-order fundamental frequency was $2.55 \mathrm{~Hz}>2.45 \mathrm{~Hz}$ (minimum of first-order fundamental frequency), which indicated that the actual dynamic stiffness of bridge was larger than the theoretical value and reduced the vibration of bridge obviously. 


\section{Conclusion}

Our national founding has passed more than 60 years and a large number of bridges have entered the old age needing maintenance and reinforcement. This aspect has greatly affected the production and life of most people in China and has a severe impact on the national economic GDP. Therefore, the new bridge reinforcement technology with the superiorities of celerity, low cost and minimal impact on the economic life is in line with the requirements of rapid economic development in China. The new technology of bridge reinforcement with prestressed CFRP plate is precisely the new technology with many advantages conforming to the development of era.

(1) Both of the tensioning equipment and the anchorage in the flexural member reinforced with the prestressed CFRP plate technology has obtained the national invention patents. This set of tensioning equipment and anchorages can reduce the slippage of the CFRP plate to a very small extent. The test result of the bridge in the process of practical bridge reinforcement indicates that the slippage and loss of creep stress of the prestressed CFRP plate are not more than $0.37 \%$.

(2) The new reinforcement bridge technology with prestressed CFRP plate has the superiorities of simple operation, short duration, obvious economic benefit and favorable reinforcement effect and its successful application for the ZhuJinDu Bridge indicates that this reinforcement method is worth promoting and applying for the domestic engineering projects of the same type. This method currently as one of the contents of "new technology of structural reinforcement" has won the "first prize in scientific and technological progress” in Hunan Province in 2012.

(3) The durability of bridge structure has drawn more and more attention of the domestic engineering field in recent years. The CFRP plate produced in accordance with the "high temperature curing" indoor process has favorable high temperature resistance, and the softening temperature generally is more than 110 degrees. While the epoxy resin at outdoor temperature began to soften at the ambient temperature of 50 degrees with a worse ultraviolet aging performance resistance. This set of anchorage invented by Hunan University has unique advantages: it depends on the domestic anchorage with high quality (identified as the leading technology in the world) for anchoring the carbon plate on the concrete surface to be stressed rather than rely on the outdoor temperature curing adhesive (organic glue) for pasting the carbon plate on the concrete surface to be stressed, the bridges reinforced with the prestressed CFRP plate generally has better durability.

\section{Acknowledgments}

Project fund: National "twelve" five scientific and technological support plan project (2011BAJ08B02).

\section{References}

[1]. JIN Yong-jun, SHANG Shou-ping, PENG Hui, et al. Prestressed carbon fiber technology in the Bridge Strengthening [J]. Highways \&Automotive Applications 2007, 122:157-159(in Chinese).

[2]. WU Zhi-ping, ZHAO Hai-dong, ZHANG Tian-tian. Application Research on Prestressed of CFRP Plates Strengthening Reinforced Composite Box Girder [J]. CONSTRUCTION TECHNOLOGY, 2013, 42(17):68-71.

[3]. HUANG Jing-qiang, LI Dong-bin, ZHAO Ji-da, et al. Experimental Research on Anchorage for CFRP Plate [J]. CONSTRUCTION TECHNOLOGY, 2010, 39(2):96-98.

[4]. GE Kai, NIU Bin, MA Lin, et al. Analysis on the applicability of CFRP in bridge strengthening engineering [J]. China Railway Science, 2006, 27(4):51-56(in Chinese).

[5]. PENG Hui, SHANG Shou-ping, ZHANG Jian-ren, et al. Fatigue behavior of reinforced concrete beams strengthened with prestressed carbon fiber reinforced polymer plates [J]. China Civil Engineering Journal, 2009, 42(8):42-49(in Chinese).

[6]. CECS146:2003, Technical Specification for Strengthening Concrete Structures with Carbon Fiber Reinforced Polymer Laminate[S] (in Chinese). 
[7]. FU Xue-yi, SUN Can. Research on the Time-dependent Stress-strain [J]. Journal of Hunan University, 2010, 37(3):13-18(in Chinese).

[8]. ACI 440.2R ERTA-2009, Guide for the Design and Construction of Externally Bonded FRP Systems for Strengthening Concrete Structures[S]. (in Chinese).

[9]. SHANG Shou-ping, LI Zhi-bin, WANG Ming, et al. Experimental Study of Reinforced Concrete Beam with Prestressed CFRP Plate [J]. Engineering Mechanics, 2008, 25(5):142-151(in Chinese).

[10]. SHANG Shou-ping, LI Zhi-bin, WANG Ming, et al. Influence of the temperature difference between day and night on the stress of prestressed CFRP plate [J]. China Civil Engineering Journal, 2009, 42(4):72-76(in Chinese).

[11]. NAN Qiuming. Application of FBG Force-testing Ring in Monitoring Cable Force of Suspension Bridge [J]. Journal of Highway and Transportation Research and Development, 2010, 27(3):64-68(in Chinese). 